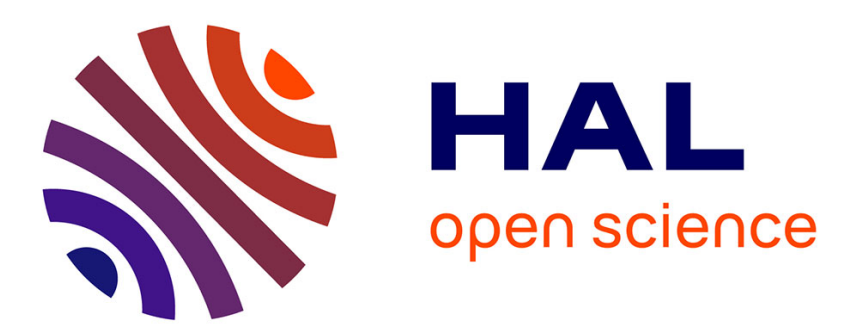

\title{
Use of lumbar point for the estimation of potential and kinetic mechanical power in running
}

Jean Slawinski, Véronique Billat, Jean-Pierre Koralsztein, Michel Tavernier

\section{To cite this version:}

Jean Slawinski, Véronique Billat, Jean-Pierre Koralsztein, Michel Tavernier. Use of lumbar point for the estimation of potential and kinetic mechanical power in running. Journal of Applied Biomechanics, 2004, 20 (3), pp.324 - 331. hal-01689785

\section{HAL Id: hal-01689785 \\ https://hal-insep.archives-ouvertes.fr/hal-01689785}

Submitted on 22 Jan 2018

HAL is a multi-disciplinary open access archive for the deposit and dissemination of scientific research documents, whether they are published or not. The documents may come from teaching and research institutions in France or abroad, or from public or private research centers.
L'archive ouverte pluridisciplinaire HAL, est destinée au dépôt et à la diffusion de documents scientifiques de niveau recherche, publiés ou non, émanant des établissements d'enseignement et de recherche français ou étrangers, des laboratoires publics ou privés. 
Use of lumbar point for the estimation of potential and kinetic mechanical power in running.

JOURNAL OF APPLIED BIOMECHANICS, 2004, 20, 324-331, 2004

SLAWINSKI Jean ${ }^{1}$

BILLAT Véronique ${ }^{1}$

KORALSZTEIN Jean-Pierre ${ }^{2}$

TAVERNIER Michel ${ }^{3,4}$

${ }^{1}$ Département STAPS, UFRSFA Université d'Evry-Val d'Essonne, Bd François Mitterand 91025 EVRY cedex.

${ }^{2}$ Centre de Médecine du Sport, CCAS, 2 avenue Richerand, 75010 PARIS.

${ }^{3}$ Fédération Française de Ski, 50 rue des Marquisats, 74011 ANNECY.

${ }^{4} \mathrm{UMR} 6610$

Running title: Centre of mass and mechanical power in running.

Key-words: Running, Numerical manikin, Kinetic and Potential energy.

Date of manuscript submission: 2003-04-28

Postal address : Slawinski Jean, Centre de Médecine du Sport, 2, avenue Richerand 75010 PARIS Tel. : 01-42-01-46-29 ; Fax : 01-42-39-20-83

E-mail : jeanslawinski@wanadoo.fr 
Abstract: The purpose of this study is to estimate the difference between potential and kinetic mechanical powers in running $\left(\mathrm{P}_{\mathrm{ke}}, \mathrm{P}_{\mathrm{pe}}\right)$ calculated from the centre of mass and one anatomic point of the body located on the lower part of the runner's back (the "lumbar point").

Six runners carried out a treadmill run at constant velocity and are filmed individually with a video camera $(25 \mathrm{~Hz})$. The $3 \mathrm{D}$ motion analysis system, ANIMAN3D, uses a numerical manikin (MAN3D) which compares a voluminal subject (the sportsman) directly to the manikin that possesses the same voluminal properties. This analysis system allows the trajectories of the centre of mass and the lumbar point to be calculated. Then, from these trajectories, potential and kinetic mechanical powers in running are calculated.

The results show that the utilisation of the lumbar point rather than the centre of mass of the runner leads to a significant overestimation of $\mathrm{P}_{\mathrm{ke}}(\mathrm{p}<0.05)$ and a significant underestimation of $\mathrm{P}_{\mathrm{pe}}(\mathrm{p}<0.05)$. However, in spite of these differences, the both methods of calculus of $\mathrm{P}_{\mathrm{ke}}$ and $\mathrm{P}_{\mathrm{pe}}$ are well correlated (respectively $\mathrm{r}=0.92 ; \mathrm{p} \leq 0.01$ and $\mathrm{r}=0.68 ; \mathrm{p} \leq 0.05$ ).

Taking into account that the trajectory of an anatomic point is experimentally easier to access than that of the centre of mass, this kind of point could be used to estimate the evolution of kinetic or potential energy variation in different cases. However, when the lumbar point rather than the centre of mass is used for the estimation of the mechanical energy produced in running, $\mathrm{P}_{\mathrm{ke}}$ could appear as a discriminating parameter, while it is not.

Words: 265. 


\section{Introduction}

The mechanical energy of running (kinetic and potential energies of the centre of mass) depends on the time course of the force that brings generates a non-uniform movement of the centre of mass. This force results from the internal forces generated by the muscles at the joints. However, the force developed by each muscle remains unknown and only a global external force resulting from internal forces generated by the different muscles of the body can be easily measured. In order to calculate the variation of mechanical energy produced by this external force, it is necessary to know the instantaneous position and speed of the runner's centre of mass. The energy value is obtained either by integration of the external forces measured with a force platform, or by derivation of the position of the centre of mass given by a $2 \mathrm{D}$ or $3 \mathrm{D}$ motion analysis system. Up to now, various studies dealing with mechanical energy have used a system of measure which not determined with precision the position of the centre of mass (Bourdin et al., 1995; Candau et al., 1998; Dalleau et al., 1998; Kyröläinen et al., 2000). Indeed, these authors use a device (kinematic arm) which determines the position of an anatomic point located on the lower part of the runner's back and which is different to the position of the centre of mass. These authors have calculated mechanical energy variation and mechanical power from this particular point. The results have shown that the mechanical energy variation is overestimated, when it is compared to the mechanical energy variation calculated with a force plate form. Bourdin et al. (1995) have suggested that "at least a part of the tilting of the trunk is recorded by the kinematic arm. As consequence horizontal kinetic energy changes would be overestimated. However, the exact reasons that could explain the mechanical energy variation overestimation are actually unknown".

This point named in the present study, as "lumbar point" (figure 1) does not represent the motion of the "real" centre of mass. This difference may explain why the mechanical energy is overestimated when it is calculated with a kinematic arm. However, no study has already 
measured the effect of the choice of an anatomical point rather than the centre of mass on the estimation of the mechanical power.

Therefore, this study aims to test the hypothesis that the use of another point rather than the centre of mass (such as the lumbar point) could lead to a significant difference in the measure of the mechanical power.
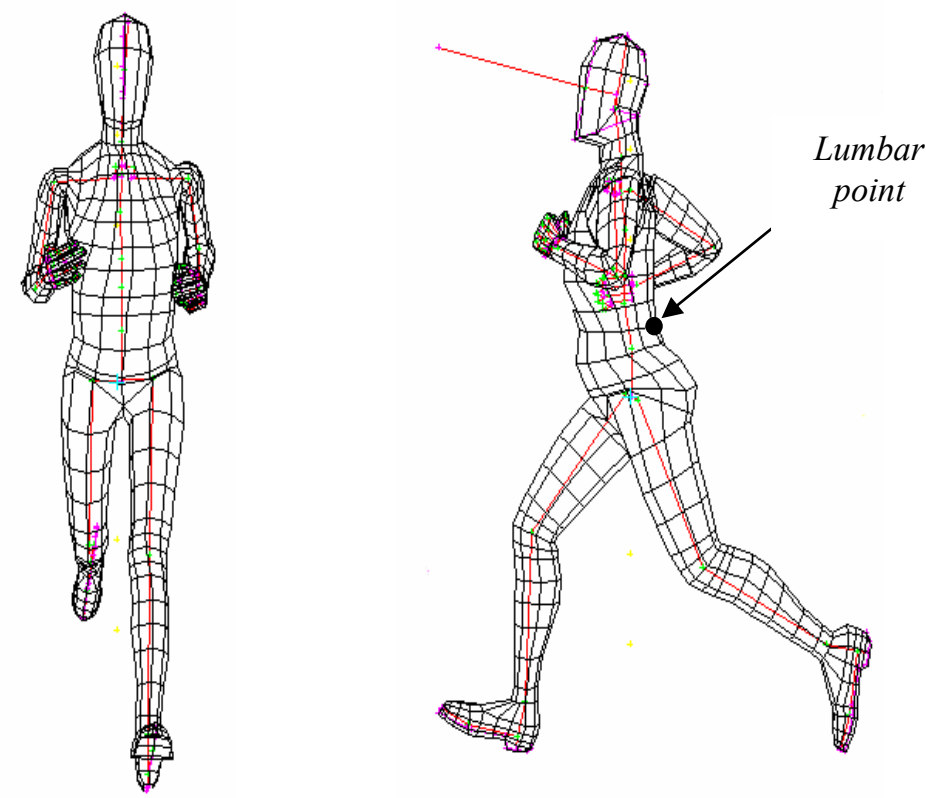

Fig. 1: 3D human manikin representation.

\section{Method}

Six runners volunteered for this survey approved by the Ethical Committee of Paris. The weight, and the size of this population were respectively $71.8 \pm 8.6 \mathrm{~kg}$ and $174.6 \pm 6.5 \mathrm{~cm}$.

The runners performed one treadmill run at a supra lactic-threshold speed at $90 \%$ of the maximal oxygen uptake $\left(5.2 \pm 0.2 \mathrm{~m} . \mathrm{s}^{-1}\right)$. During this test, the runners were filmed from the left side, two strides were analysed three minutes after the beginning of the exercise and two more one minute before the end (the exercise duration was $13 \min 4 \mathrm{~s} \pm 3 \min 15 \mathrm{~s}$ ). Therefore 
two measures of the kinetic and potential mechanical power produced in running were obtained for each runner.

All the tests were performed on a horizontal motorised treadmill (Gymrol 1800, Techmachine, Saint-Etienne, France). The speed of the belt was controlled with controller provided by the CDEMS, (Université Joseph Fourier, Grenoble, France). During the constant intensity test, the runners were filmed with a video camera using a sampling frequency of 25 images by second.

The video sequences obtained, were digitised without geometrical distortion on a PC as a series of bitmap images with a Perception Video Recorder card from Silicon Co. The 3D motion analysis system (ANIMAN3D, Tavernier et al. 1997) uses the numerical human model MAN3D (Verriest 1991; Verriest et al. 1997; figure 1). The position and posture of MAN3D can be adjusted to each runner. In order to get the best possible precision, the morphological properties of MAN3D are deduced from the size and the weight of the subject. The inertial properties of the limbs are from works of Dempster and Gaughran 1967.

Then MAN3D is superimposed to the images of the runner, the position and posture of the runner are the same as that of MAN3D. The software, ANIMAN3D, determined the trajectories of the anatomic points of the manikin, and the trajectory of the body centre of mass. Kinetic and potential mechanical powers are calculated from the centre of mass of the body and one anatomic point of the body located on the lower part of the runner's back (the “lumbar point”: figure 1).

The vertical and horizontal trajectories of the centre of mass, of the lumbar point and of the body centre of mass were smoothed using a polynomial method (Tavernier et al. 1996) in order to obtain by derivation, the speed of the two points, and their mechanical energy. The 
polynomial degree was determined individually for the trajectory of the centre of mass and of the lumbar point of each subject.

These analyses were carried out in two dimensions. $\Delta \mathrm{E}_{\mathrm{ke}}$ can be disregarded in the transversal axis, because in this direction the amplitude of the motion is negligible (Cavagna and Kaneko, 1977). Potential and kinetic mechanical power were calculated as the sum of positive energy variations, according to the following equation:

$$
\begin{aligned}
& \Delta \mathrm{E}_{\mathrm{pe}}=\mathrm{M} \times \mathrm{g} \times\left(\mathrm{H}_{\text {max }}-\mathrm{H}_{\text {min }}\right) \\
& \Delta \mathrm{E}_{\mathrm{ke}}=\frac{1}{2} \mathrm{M} \times\left(\mathrm{V}_{\text {max }}^{2}-\mathrm{V}_{\text {min }}^{2}\right)
\end{aligned}
$$

"M" is the body mass $(\mathrm{kg})$, " $\mathrm{g}$ " is the gravitational acceleration $\left(9.81 \mathrm{~m} . \mathrm{s}^{-2}\right), " \mathrm{H}_{\max }$ and $\mathrm{H}_{\min }$ " are maximal and minimal heights of the body centre of mass $(\mathrm{CM})$ during one step (m). "V $\mathrm{max}$ and $\mathrm{V}_{\min }$ " are the maximal and minimal horizontal velocities of the CM during one step (m.s $\left.{ }^{1}\right) . \Delta \mathrm{E}_{\mathrm{ke}}$ and $\Delta \mathrm{E}_{\mathrm{pe}}$ are also calculated from the trajectory of the lumbar point.

This procedure has been done by numerous authors (Cavagna and Kaneko, 1977; Willems et al; 1995; Candau et al. 1998). Only the energy necessary to lift and accelerate forward the centre of mass or the lumbar point was considered. Then, kinetic and potential energy variations are divided by the stride time to be expressed in Watt, and named respectively, kinetic mechanical power $\left(\mathrm{P}_{\mathrm{ke}}\right)$ and potential mechanical power $\left(\mathrm{P}_{\mathrm{pe}}\right)$.

The statistical analysis is done using the Wilcoxon non-parametric test. The mechanical power of the centre of mass is compared with that of the lumbar point. Correlation between the two methods of calculus of $\mathrm{P}_{\mathrm{ke}}$ and $\mathrm{P}_{\mathrm{pe}}$ were also calculated with a Spearman test. The statistical significance is set at $\mathrm{p}=0.05$. 


\section{Results}

The statistical analyses shows that the kinetic mechanical power calculated from the movements of the centre of mass is significantly lower (about 50\%; p $\leq 0.01$ ) than that calculated from the movements of the lumbar point (fig. 2a; table 1). In the same way, the potential mechanical power calculated from the movement of the centre of mass is significantly higher (about $12 \% ; \mathrm{p} \leq 0.01$ ) than that calculated from the movement of the lumbar point (fig. 2b; table 1). However, in spite of these differences, the both methods of calculus of the kinetic and potential mechanical powers are well correlated (respectively $\mathrm{r}=$ $0.92 ; \mathrm{p} \leq 0.01$ and $\mathrm{r}=0.68 ; \mathrm{p} \leq 0.05)$.

Figure 3 shows the characteristic horizontal (a) and vertical (b) trajectory of the body's centre of mass and of the lumbar point during four steps. This figure suggested that the amplitude of horizontal movement of the centre of mass of the body is smaller than that of the lumbar point. However, the vertical displacement of the centre of mass is similar to the vertical displacement of the lumbar point. 

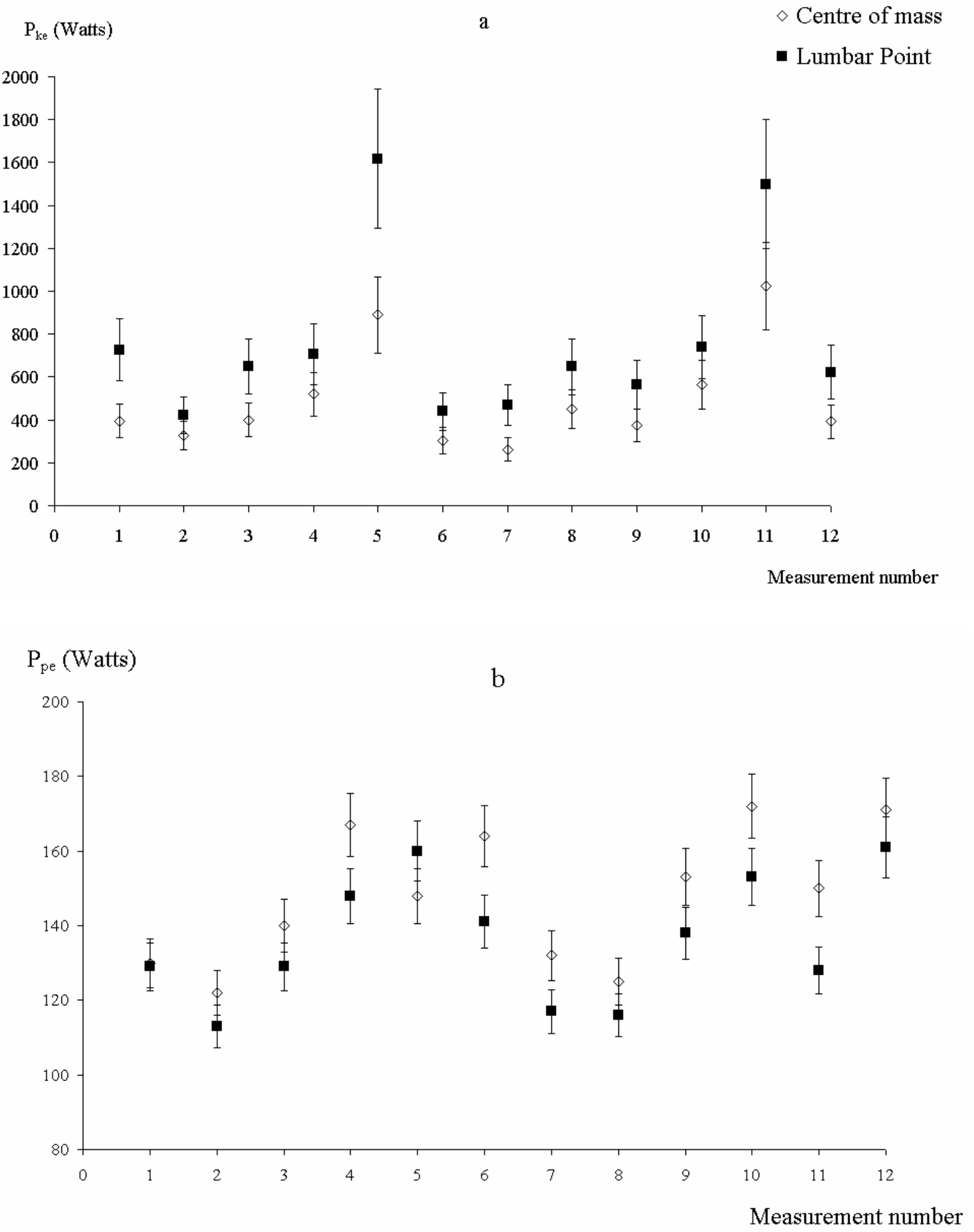

Fig. 2a, b: Kinetic (a) and potential (b) mechanical power $\left(\mathrm{P}_{\mathrm{ke}}\right.$ and $\left.\mathrm{P}_{\mathrm{pe}}\right)$ of the centre of mass (CM) and the lumbar point (LB), for each measurement. The vertical bars represent the uncertainties in $\mathrm{P}_{\mathrm{ke}}$. 

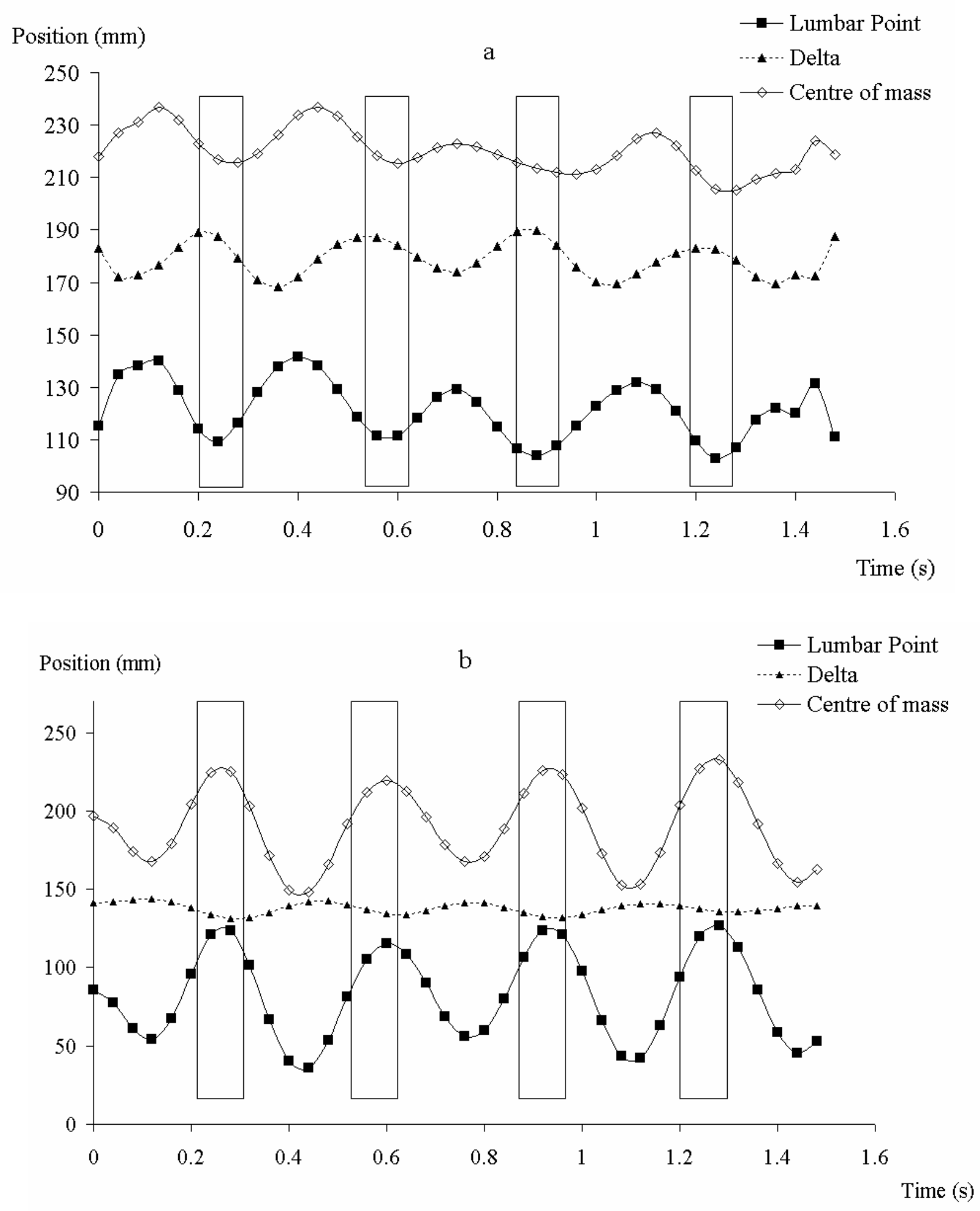

Fig. 3a, b: Characteristic horizontal (a) and vertical (b) fitted trajectory of the body's centre of mass and of the lumbar point of a runner. 


\begin{tabular}{|c|c|c|c|c|c|c|}
\hline & $\begin{array}{c}\text { Cavagna et } \\
\text { Kaneko, } 1977 \\
\text { (Force plate } \\
\text { form) }\end{array}$ & $\begin{array}{c}\text { Willems et al., } \\
1995 \\
\text { (Force plate } \\
\text { form) }\end{array}$ & $\begin{array}{c}\text { Bourdin et al., } \\
1995 \\
\text { (kinematic } \\
\text { arm) }\end{array}$ & $\begin{array}{c}\text { Candau et al., } \\
1998 \\
\text { (kinematic } \\
\text { arm) }\end{array}$ & $\begin{array}{c}\text { The present } \\
\text { study } \\
(C M)\end{array}$ & $\begin{array}{c}\text { The present } \\
\text { study } \\
\text { (Lumbar } \\
\text { point) }\end{array}$ \\
\hline$P_{k e}(W)$ & 293 & 280 & 839 & 617 & 492 & 759 \\
\hline$P_{p e}(W)$ & 157 & 150 & 172 & 153 & 148 & 136 \\
\hline$P_{k e}+P_{p e}(W)$ & 450 & 430 & 1011 & 770 & 640 & 895 \\
\hline
\end{tabular}

Table 1 : Potential and kinetic power $\left(\mathrm{P}_{\mathrm{pe}}\right.$, and $\left.\mathrm{P}_{\mathrm{ke}}\right)$ in running generally encountered in the literature, for a speed of about $5 \mathrm{~m} \cdot \mathrm{s}^{-1}$.

\section{Discussion}

The results show that the utilisation of the lumbar point rather than the centre of mass of the runner leads to a significant overestimation of the kinetic mechanical power and a significant underestimation of the potential mechanical power. However, in spite of these differences, the both methods of calculus of the kinetic and potential mechanical powers are well correlated.

The comparison of the kinetic and potential mechanical powers calculated with ANIMAN3D, with those of the literature (table 1) shows that potential mechanical power is similar for all studies. However, the kinetic mechanical power calculated in the present study is higher than the kinetic mechanical power measured with a force plate form of about $200 \mathrm{~W}(40 \%)$. These differences may firstly be explained with individual characteristics of the subjects used in the different studies. Secondly, large changes in mechanical power values, evaluated by video analysis, are related to changes in the cutoff frequency or to the choice of the smoothing polynomial degree (Williams and Cavanagh, 1983). Moreover, the uncertainty associated to the determination of the trajectory of the body centre of mass with a video camera, especially during the flight phase, may also explain the great difference between video and force plate form analysis. 
However, great differences exist between the kinematic arm and the other systems of measure (Bourdin et al., 1995). The table 1 shows that when the kinetic mechanical power is calculated with the parametric trajectory of the lumbar point little differences exist with the kinetic mechanical power calculated with the kinematic arm. Now, the kinematic arm computes the instantaneous displacement of the lumbar point of the runner and the results of the present study show that the kinetic mechanical power is greater when is calculated with the lumbar point. Therefore, the choice of the lumbar point as reference rather than the centre of mass leads to an overestimation of the kinetic mechanical power. The difference observed between the kinetic mechanical power calculated with the centre of mass and the kinetic mechanical power calculated with the lumbar point is associated with different trajectories of the two points. Indeed, the lumbar point is a fixed point that follows all the movements of the trunk. Contrariwise, the centre of mass is not a fixed point and its movement is smaller than that of the lumbar point (Fig. 3a). As the position of the centre of mass is calculated from the position of the centre of mass of the body segments and as the instantaneous position of the lumbar point depends of the movements of the trunk, the horizontal instantaneous position of both points is necessarily different. Notably during the flight phase when the horizontal position of the centre of mass can not be modified by the movement of the segments, while the horizontal position of the lumbar point can be modified by the movement of the trunk.

Similarly the estimation of the potential mechanical power is modified according to the point chosen. Indeed, the potential mechanical power calculated from the trajectory of the centre of mass is $12 \%$ greater compared to the potential mechanical power calculated from the trajectory of the lumbar point. These differences are also associated with the different vertical instantaneous position of both points. 
The choice of an anatomic point rather than the centre of mass of the runner has a large influence on the calculation of the kinetic mechanical power, but less influence on the potential mechanical power. The utilisation of the lumbar point rather than the centre of mass for the estimation of the "external" mechanical energy produced in running $\left(\mathrm{W}_{\text {ext }}\right)$, could give to the kinetic mechanical power a greater importance compared to the potential mechanical power. This overestimation of the kinetic mechanical power, may explain why only the authors using a kinematic arm find significant correlations between the mechanical energy variation and the energy cost of running.

The comparison of the kinetic and potential mechanical powers between studies or subjects has to take into account the method of measured used. Indeed, the present study demonstrates that the use of a different method of measure (use of lumbar point, rather than the centre of mass) can lead to $50 \%$ of overestimation of the kinetic mechanical power and $12 \%$ of underestimation of the potential mechanical power. A mechanical analysis and calculation of the mechanical energy during a run could only be carried out using equipment that allows a precise location of the runner's centre of mass. Nevertheless, taking into account that the trajectory of an anatomic point is experimentally easier to access than that of the centre of mass, this kind of point could be used to estimate the evolution of kinetic or potential energy variation in different cases. This study can help a future methodology to quantify the accuracy during calculation of using another point near the centre of mass.

\section{Words: 2065}

\section{References}

Bourdin, M., Belli, A., Arsac, L. M., Bosco, C., Lacour, J. R. (1995). Effect of vertical loading on energy cost and kinematics of running in trained male subjects. J. Appl. Physiol. 
$79,2078-85$.

Candau, R., Belli, A., Millet, G., Georges, D., Barbier, B., Rouillon, J. (1998). Energy cost and mechanics during a treadmill run to voluntary exhaustion in humans. Eur. J. Appl. Physiol. 77, 479-485.

Cavagna, G., and Kaneko, M. (1977). Mechanical work and efficiency in level walking and running. J. Physiol. 268, 467-481.

Dalleau G., Belli A., Bourdin M., Lacour J.R. (1998). The spring-mass model and the energy cost of treadmill running. Eur. J. Appl. Physiol. Occup. Physiol. 77, 257-63.

Dempster W., Gaughran G. (1967). Properties of body segments based on size and weight. Am. J. Anat. 120; 33-54.

Kyröläinen H., Pullinen T., Candau R., Avela J., Huttunen P., Komi P. (2000). Effects of marathon running on running economy and kinematics. Eur. J. Appl. Physiol. 82, 297-304.

Tavernier, M., Cosserat, P., Ruby, A. (1996). Optimisation de l'ajustement de trajectoires par lissage avec des polynômes d'ordres multiples élevés : Comparaison avec le filtre de butterworth du second ordre. Science et Motricité. 28, 53-56.

Tavernier, M., Cosserat, P., Emmendoerffer, S., Ruby, A., Lavest, J. M., Dhome, M., Verriest, J.P. A 3D (1997). Motion analysis system using a numerical human model. In proceedings of the ISBC. Tokyo.

Verriest, J.P. (1991). MAN3D: a functional and geometrical model of the human operator. IFIESR, congress Lake Tahoe USA. Ed. W. Karwowski \& J. W. Yates pp 901 - 908

Verriest J.P, Wang X, Trasbot J., Tessier Y. (1994). Application of 3D human model to computer aided engineery design of vehicules. In: Proceeds of Fisita (engineering for custumers) pp 53-61. 
Willems P.A., Cavagna G.A., Heglund N.C. (1995). External, internal and total work in human locomotion. J. Exp. Biol. 198, 379-393.

Williams K.R., Cavanagh P.R. (1983). A model for the calculation of mechanical power during distance running. J. Biomech. 16; 115-28. 
